\title{
Developing treatment for adrenocortical carcinoma
}

\author{
T M A Kerkhofs', M H T Ettaieb ${ }^{1}$, I G C Hermsen ${ }^{1}$ and H R Haak ${ }^{1,2,3}$ \\ ${ }^{1}$ Department of Internal Medicine, Maxima Medical Center, Ds. Th. Fliednerstraat 1, 5631 BM Eindhoven/Veldhoven, \\ The Netherlands \\ ${ }^{2}$ Division of General Internal Medicine, Department of Internal Medicine, Maastricht University Medical Centre + , \\ Maastricht, The Netherlands \\ ${ }^{3}$ Department of Health Services Research and CAPHRI School for Public Health and Primary Care, \\ Maastricht University Medical Center, The Netherlands
}

Correspondence

should be addressed

to T M A Kerkhofs

Email

t.kerkhofs@mmc.nl

\begin{abstract}
Cancer of the adrenal cortex (ACC) is a rare endocrine malignancy with limited treatment options. Patients typically present with autonomous hormonal overproduction and/or a large abdominal mass. Hormonal assays and medical imaging can be diagnostic, but urinary steroid profiling might be a more sensitive technique to assess malignancy in adrenal tumours. The stage of the disease at diagnosis is the most important prognostic factor. The current staging system needs refinement, especially to separate aggressive from indolent disease in stage IV patients and to select patients who need adjuvant treatment after complete surgical resection. Regarding the latter, assessing the proliferation index Ki-67 seems the best tool currently available. Genomic profiling is expected to become of clinical relevance in the future. Medical therapy is centred on the adrenolytic drug mitotane, which carries considerable toxicity and is not easy to manage. Its tolerability and long plasma level build-up phase may be improved by therapeutic drug monitoring based on pharmacokinetic modelling and intensive counselling of patients. Current chemotherapy regimens can offer disease stabilization in about $50 \%$ of patients, but an objective response should be expected in $<25 \%$. Research on targeted therapy and immunotherapy is difficult in this rare disease with often heavily pre-treated patients and has not yet been successful. Quality of care should be ensured by treating patients in centres with established experience in multidisciplinary oncologic care, who adhere to prevailing guidelines and state-of-the-art in diagnostic and treatment concepts. International collaboration in fundamental research and clinical trials is the key to further elucidate the pathogenesis and to improve patient care.
\end{abstract}

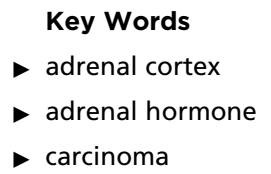

Endocrine-Related Cancer (2015) 22, R325-R338

\section{Introduction}

Cancer of the adrenal cortex (ACC) occurs in about 1-2 people per million, which renders it a rare endocrine malignancy (Kebebew et al. 2006, Fassnacht \& Allolio 2009). Complete surgical resection is the sole curative option. In about half of all patients this is impossible because of presentation with metastasized disease (Kerkhofs et al. 2013a). Moreover, recurrent disease occurs in $\sim 60 \%$ of operated patients according to national database studies (Hermsen et al. 2012, Erdogan et al. 2013). Upon presentation, prognosis is mainly determined by the stage of disease. Patients with localized disease have a 5-year survival of $60-80 \%$, in patients with locally advanced disease this rate drops to $35-50 \%$. In metastasized disease, prognosis varies from 13 to $28 \%$, but heterogeneity in this

Published by Bioscientifica Ltd. 
group precludes an adequate estimation (Fassnacht et al. 2009, Kerkhofs et al. 2013a, Tran et al. 2013). The cornerstone of medical treatment is mitotane, a 55-yearold drug that is derived from an agricultural insecticide (Lubitz et al. 1973). The aim of this review is to discuss changes we foresee in diagnostic and prognostic instruments, as well as suggestions for clinical management and possibilities for future treatment of ACC.

\section{Diagnostics}

ACC patients may present with symptoms of an abdominal mass, symptoms related to autonomous hormonal production by the tumour, or both. In rare cases, ACC is discovered incidentally during diagnostic tests or medical imaging for reasons unrelated to the adrenal glands. Figure 1 contains a flowchart of the diagnostic work-up of patients with suspect ACC. Data on the incidence of hormonal overproduction in ACC differ, as some studies report clinical symptoms in symptomatic patients and others report biochemical results. Clinical symptoms caused by autonomous and excessive production of glucocorticoids alone occur in about $30 \%$ of patients according to an international multi-center study (Berruti et al. 2014). Interestingly, studies based on biochemical results report a lower rate of isolated glucocorticoid overproduction: 14-20\% (Berruti et al. 2005, Abiven et al. 2006). The discrepancy may be explained by underestimation of combined glucocorticoid/androgen excess in the multi-center clinical study, given the reported rates of $8.3 \%$ vs $23-36 \%$ in the biochemical studies mentioned before. After all, biochemical analysis is expected to have higher sensitivity for hormonal abnormalities compared to clinical examination only. Overproduction of androgens alone was reported in 5-20\% (Berruti et al. 2005, 2014, Abiven et al. 2006). Overproduction of oestrogens, mineralocorticoids or other steroid combinations is rare, being diagnosed in $<5 \%$ of patients. In $23-31 \%$ (after endocrine work-up) to $48 \%$ (based on clinical evaluation) of all ACC patients, hormonal overproduction is not apparent upon presentation. These patients typically seek medical attention because of abdominal pain, fullness or a palpable mass. Non-specific symptoms related to malignancy such as weight loss, night sweats or fever may also be present (Berruti et al. 2014). Research suggests that despite absence of clinically apparent hormonal overproduction, these tumours do produce excess steroid precursors such as tetrahydro-11-deoxycortisol (THS), pregnanediol (P2),

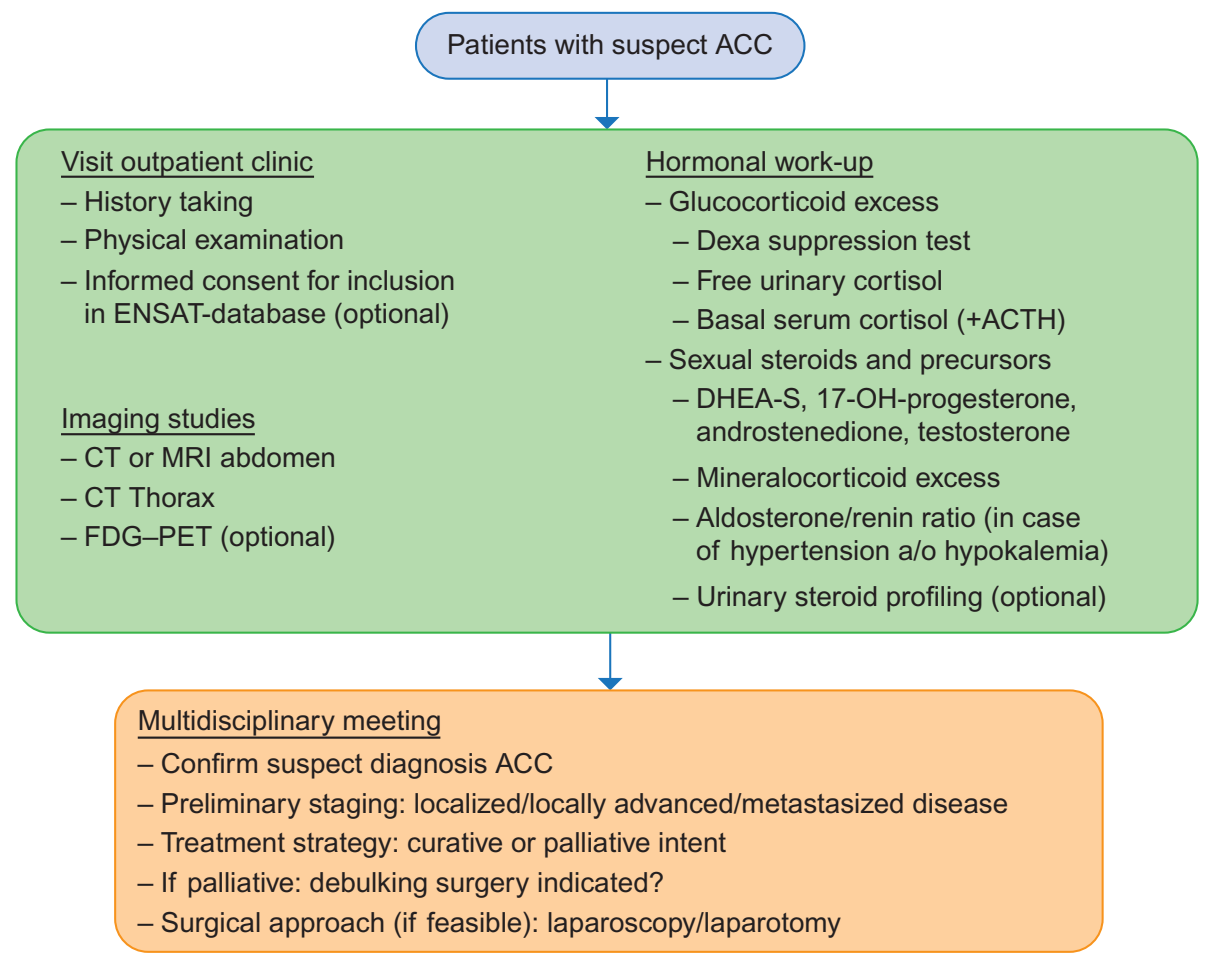

Figure 1

Diagnostic work up of patients with suspect adrenocortical carcinoma. 
pregnanetriol (P3) and etiocholanolone (E) (Arlt et al. 2011). Examination of urine samples using highly sensitive methods such as gas chromatography/mass spectrometry (urinary steroid profiling (USP)) is able to detect small amounts of these substances. Retrospective studies suggest that THS excretion $>2.35 \mu \mathrm{mol} / 24 \mathrm{~h}$ could be diagnostic for the presence of ACC (Kerkhofs et al. 2015a). Also, USP can be used to distinguish ACC from adenomas with degenerative or regressive characteristics on imaging (Perna et al. 2014). We expect the diagnostic value of USP will be confirmed in prospective trials and this technique will gain a place in the diagnostic armamentarium used in analysing patients with adrenal tumours. A prospective study aimed at assessing cost-effectiveness of USP in the work-up of adrenal tumours is currently recruiting (Structured Evaluation of adRENal Tumors Discovered Incidentally - Prospectively Investigating the Testing Yield (SERENDIPITY trial), NCT02324647). A secondary objective is to assess the frequency of ACC among patients with adrenal incidentaloma at baseline or during followup. It is tempting to speculate that urinary excretion of steroid precursors could be a marker for disease recurrence and/or occurrence of metastases. Following this reasoning, it is not inconceivable that urinary samples could eliminate the need of frequent CT scans and the associated exposure to ionizing radiation. Further research will have to determine whether USP has adequate sensitivity for recurrent disease in post-operative follow-up of patients with ACC. Another promising technique is the measurement of circulating tumour cells in the bloodstream. Although difficult to detect in peripheral blood, these cells are considered to be an early marker of metastatic disease in several solid tumours and possibly a marker of therapeutic response. Thanks to technical advances, methods of detection are improving, which results in increased sensitivity and specificity (Sun et al. 2011). In a recent preliminary study among 24 patients with adrenal tumours, circulating tumour cells were detected in all ACC patients, but not in patients with an adrenal adenoma (Pinzani et al. 2013). Additional larger studies are needed, since this technique seems potentially valuable as a marker for detection of malignancy and perhaps even for disease progression or treatment monitoring.

\section{Clinical prognostic factors}

Currently, the most important prognostic factor in ACC is the stage of disease at presentation (Fassnacht et al. 2009). The European Network for the Study of Adrenal Tumours (ENSAT) staging system was introduced in 2009 and proved to be superior to the International Union Against Cancer (UICC) staging system in a 2010 validation study (Lughezzani et al. 2010). Additional prognostic factors are needed, since the ENSAT system does not result in a differentiation firm enough to base important treatment decisions on.

\section{Localized disease}

Overall survival was not significantly different between patients with ENSAT stages I and II disease in validation studies (Lughezzani et al. 2010). In this group, the main question is which patients should receive adjuvant treatment after surgery. The immunohistochemical proliferation marker Ki-67 (Mib1) is regarded as the most promising prognostic factor to be included in standard work-up of ACC patients (McNicol et al. 1997, Terzolo et al. 2001, Sasano et al. 2006, Morimoto et al. 2008). A retrospective study among 569 patients with disease stages I-III who underwent a complete resection including an independent validation cohort demonstrated that Ki-67 is associated with recurrent disease (hazard ratio (HR) 1.042 per 1\% increase) and overall survival (HR for death, 1.051) (Beuschlein et al. 2015). The authors suggest clinical application of the Ki-67 index based on expression in tumour tissue of $<10 \%, 10-19 \%$ and $\geq 20 \%$. There are limitations to clinical application of the Ki- 67 index that deserve further attention. Research shows that interobserver variability in determining the index is high, even when performed by expert pathologists. Preliminary results suggest that automated software assessment of the Ki-67 index may result in more consistent results and better correlation with clinical outcome (Pucci et al. 2014). In addition, Ki- 67 proliferation within a single tumour is characterized by a highly heterogeneous pattern. Fields with highly proliferative cells are often surrounded by areas of non-staining cells or even necrosis, which holds a significant risk of sampling error. Therefore, a uniform methodology for assessing the Ki-67 index in ACC needs to be established.

\section{Advanced disease}

A second shortcoming of the ENSAT staging system is considerable heterogeneity in the stage IV group. In some patients the disease progresses aggressively and hardly responds to treatment. As a result, survival is only a few weeks or months (Kerkhofs et al. 2013a). In other patients, the disease follows a more indolent course and survival of up to several years has been observed

Published by Bioscientifica Ltd 
(Hermsen et al. 2008). The search for clinical predictors of survival in these patients is still ongoing. Several parameters have been suggested, such as age, mitotic rate or presence of autonomous hormone production (Abiven et al. 2006, Assie et al. 2007). A recent retrospective study from the ENSAT ACC working group proposes a modification of the ENSAT staging system regarding patients with stage III-IV disease (Libe et al. 2015). In this proposal, stage IV is divided in three subgroups (A, B and C, Table 1). Patients with $\mathrm{T}_{3-4} \mathrm{~N}_{1} \mathrm{M}_{0}$ disease shift from stage III to stage IV-A. Also in IV-A are patients with $\mathrm{T}_{1-4} \mathrm{~N}_{0-1} \mathrm{M}_{1}$, as long as no more than two different organs are affected (including lymph node metastases). Patients with $\mathrm{T}_{1-4} \mathrm{~N}_{0-1} \mathrm{M}_{1}$ and three affected organs form group IV-B, all other patients (i.e., $\mathrm{T}_{1-4} \mathrm{~N}_{0-1} \mathrm{M}_{1},>3$ organs) form group IV-C. In addition, the prognostic significance of four parameters was validated in a large cohort of stage III-IV patients $(n=349)$. Tumour grade (G) was proposed as a binomial parameter defined as Weiss $\leq 6$ and Ki- $67<20 \%$ or Weiss $>6$ and/or Ki-67 >20\%). Resection status (R), also binomial, was defined as complete resection $\left(\mathrm{R}_{0}\right)$ or other. Age (A) below 50 years had a favourable effect on overall survival. Functional symptoms (F) were defined as the presence of tumour- or hormone-related symptoms at diagnosis. The exact role of these parameters in further stratification of patients with advanced ACC will have to be established in future studies. It is expected that the differentiation between stage IV-A, B and C will have consequences for treatment initiation, for example to start with mitotane monotherapy in metastatic disease with relatively favourable characteristics, but start immediate combination chemotherapy in metastasized disease with unfavourable features.

\section{Genetic prognostic factors}

In addition to establishing clinical prognostic factors, research is focused on the emerging possibilities of genomic characterization of tumours. Gene expression profiling on large cohorts of adrenal tumours identified among ACCs two distinct subgroups that differed in

Table 1 Proposal for modified ENSAT staging system (Libe et al. 2015)

\begin{tabular}{|c|c|}
\hline Stage & Definition \\
\hline III & $\mathrm{T}_{3-4} \mathrm{~N}_{0} \mathrm{M}_{0}$ \\
\hline IV-A & $\begin{array}{l}\mathrm{T}_{1-4} \mathrm{~N}_{1} \mathrm{M}_{0} \text { or } \mathrm{T}_{1-4} \mathrm{~N}_{0-1} \mathrm{M}_{1}(\mathrm{max} \text {. } \\
\text { two organs including } \mathrm{N} \text { ) }\end{array}$ \\
\hline IV-B & $\mathrm{T}_{1-4} \mathrm{~N}_{0-1} \mathrm{M}_{1}$ (three organs) \\
\hline IV-C & $\mathrm{T}_{1-4} \mathrm{~N}_{0-1} \mathrm{M}_{1}$ (>3 organs) \\
\hline
\end{tabular}

http://erc.endocrinology-journals.org DOI: 10.1530/ERC-15-0318

(C) 2015 Society for Endocrinology Printed in Great Britain long-term overall survival, while distinguishing histological features could not be found (De Reynies et al. 2009, Giordano et al. 2009). In an effort to further characterize genomic alterations in ACC, a study combined exome sequencing, SNP arrays, DNA methylation analysis, mRNA expression arrays and miRNA sequencing (Assie et al. 2014). Two clusters were identified based on mRNA expression that were associated with clinical outcome, i.e., overall survival. Tumours from the cluster with poor outcome (named C1A) could subsequently be divided in three groups based on DNA methylation profile. In this particular example, DNA methylation refers to hypermethylation of cytosine-guanine dinucleotides (CpG). A region of DNA with a high frequency of CpG sites is called a CpG island. If hypermethylation of CpG islands occurs in the promotor region of a specific gene (for example, a tumour suppressor gene), this may cause their dysfunction. In accordance with observations in colon cancer, subsets of hypermethylated ACCs have been identified and labelled CpG island methylator phenotype (CIMP) (Barreau et al. 2013). Hence, the three subgroups in the C1A cluster are labelled CIMP-high, CIMP-low and non-CIMP. Tumours from the cluster with indolent course of disease (named C1B) could be further divided in two groups based on miRNA expression (Mi1 and Mi2). Earlier research also suggested circulating miRNA was associated with clinical outcome: high levels of miR-483-5p and low levels of miR-195 were correlated with shorter recurrencefree and overall survival (Chabre et al. 2013). Analysis of suspect driver genes and pathways revealed most alterations in the subgroup with poor clinical outcome, as well as a higher mutation rate. It appears that inter-individual differences are large, given that the most frequently altered gene (ZNRF3, related to the $\beta$-catenin pathway) was altered in $21 \%$ of cases (Assie et al. 2014). It is expected that further genomic characterization will lead to increased understanding of ACC pathogenesis. In the future, genomic characterization of ACC is expected to be of prognostic value and improve clinical management. For example, an unfavourable genomic profile might warrant aggressive adjuvant (chemo)therapy and close surveillance, whereas a favourable profile could justify more lenient follow-up. In addition we expect improved understanding of the pathogenesis will also yield therapeutic targets and thus therapeutic possibilities.

\section{Organization and quality of care}

Concentration of care in a limited number of specialized hospitals aimed at improving outcomes is an important

Published by Bioscientifica Ltd 
concept in general healthcare, but particularly in oncological care, high-risk surgical care and rare diseases. Regarding ACC, increasing evidence suggests that establishment of (inter)national collaborative networks of expert centres has a favourable effect on survival (Fassnacht et al. 2010, Lombardi et al. 2012, Kerkhofs et al. 2013b). The concept that rare diseases should be treated in a limited number of specialized hospitals seems intuitively logical. Interestingly, a better outcome of oncological treatment in specialized centres is not necessarily correlated with volume requirements (Ho et al. 2012). Similar observations were reported in highrisk surgical treatment (Finks et al. 2011). Moreover, common minimum volume requirements as instituted for other cancers are hardly feasible for ACC due to the low incidence. For example, the number of new patients with ACC per year in The Netherlands is about 20 (median 21, range 13-26 between 1993 and 2010). Although the number of surgical procedures for suspect adrenal malignancy will be higher, the grand total is expected to be too low to institute meaningful minimum volume requirements. Of course, numbers are higher in other (bigger) countries, but it is questionable whether geographical spread would allow for concentration of care on this scale. We expect quality criteria other than volume are of greater importance in rare diseases. It seems more important that centres adhere to current state-of-art treatment concepts, which in turn seems best feasible in specialized centres with dedicated physicians. Experience with multidisciplinary oncologic surgery and, preferably, adrenal/endocrine surgery is a strong recommendation and maybe even be a prerequisite. In addition, participation in international networks and clinical trials should be encouraged. By doing so, local specialists remain up to date and rapid adjustments can be made while respecting national and local regulations. Figure 2 contains a flowchart depicting current treatment strategy in which multidisciplinary decision-making has a key role. The following paragraphs discuss the steps of this treatment algorithm and highlight several possibilities for future improvement. Table 2 should be regarded as supplement to Figs 1 and 2 and summarizes the considerations that in our view should be part of current state-of-the-art diagnostic and treatment concepts in ACC.

\section{Surgery: the primary treatment modality}

In patients who present with local or locally advanced disease, curative treatment is possible by performing complete surgical resection (Schulick \& Brennan 1999, Grubbs et al. 2010). In practice, this is not as straightforward as it may seem. In the first place, completeness of

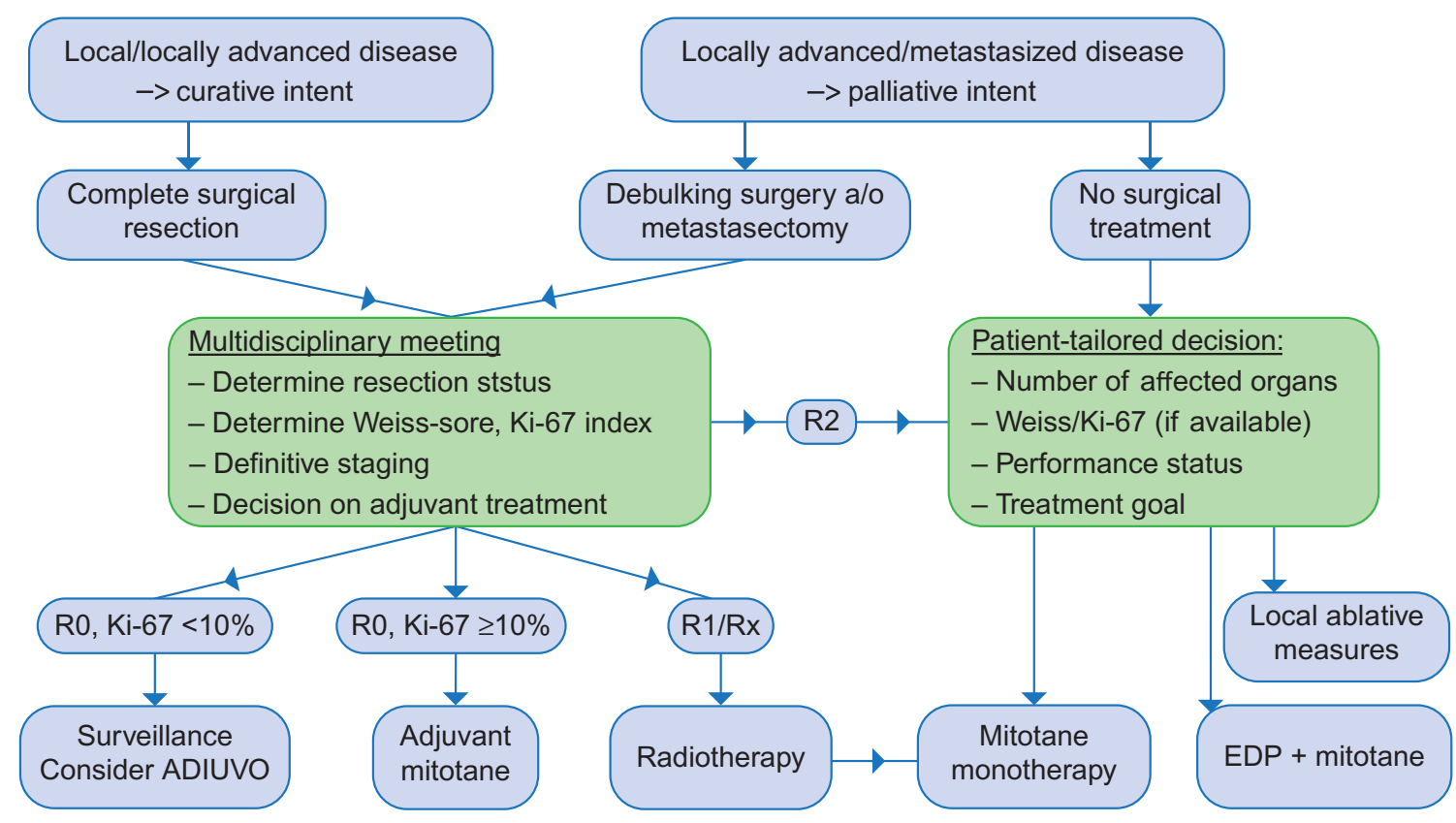

Figure 2

Treatment algorithm for patients with adrenocortical carcinoma. R0, complete resection; R1, microscopic residual tumour; R2, macroscopic residual tumour; $\mathrm{Rx}$, resection status undetermined; EDP, etoposide/
(C) 2015 Society for Endocrinology Printed in Great Britain doxorubicin/cisplatin; ADIUVO, Clinical trial testing efficacy of adjuvant mitotane treatment in prolonging recurrence-free survival in patients with adrenocortical carcinoma at low-intermediate risk of recurrence.

Published by Bioscientifica Ltd. 
Table 2 Summary of considerations that should be part of current state-of-art diagnostic and treatment concepts in adrenocortical carcinoma

Step in algorithm
$\begin{aligned} & \text { Diagnostics in patients with suspect ACC (Fip } \\ & \text { Hormonal work-up }\end{aligned}$
Pre-operative multidisciplinary meeting
Treatment algorithm (Fig. 2)
Surgery
Post-operative multidisciplinary meeting

Post-operative multidisciplinary meeting

Surveillance

\section{Consider ADIUVO}

Adjuvant mitotane

Radiotherapy

Patient-tailored decision in metastatic disease

Mitotane monotherapy

Local ablative measures

$\mathrm{EDP}+$ mitotane

Optional: research facilitation

Obtain informed consent to store and share clinical data for future research

Obtain informed consent to store and share tumour tissue, blood sample, urine sample for future research

Store freshly frozen sample of tumour tissue

\section{Consideration}

Urinary steroid profiling can be of added value in patients with inconclusive imaging results

Takes place within 2 weeks after completion of diagnostic tests

Attended by endocrinologist, oncologist, surgeon and radiologist

Adrenalectomy within 3 weeks after multidisciplinary meeting

Resection status is determined by discussing surgeon's and pathologist's observations and conclusions

Pathology report contains itemized Weiss-score and Ki-67 index

Lymph node involvement is determined

Definitive ENSAT-stage is determined

FDG-PET scan performed 3-6 months after (complete) resection of primary tumour

Possibility to enrol patients in (international) trials

Treatment instituted according to protocol (Fig. 3) and maintained for at least 2 years

Consider total dose $>40$ Gy with single fractions of 1.8-2 Gy (including boost volume to reach 50-60 Gy in individual patients) (Polat et al. 2009)

Consider cut-off values for number of affected organs from least to worst risk: 2, 3 or $>3$ (Libe et al. 2015)

Weiss-score $>6$ and/or Ki-67 $>20 \%$ correlates to most aggressive behaviour (Libe et al. 2015)

Consider performance status ECOG 2 or better as baseline before EDP-M treatment

Treatment goal: take into account patient's wishes and expectations

Treatment instituted according to protocol (Fig. 3)

Consider radio-frequency ablation, stereotactic body radiation therapy or surgical resection of oligometastases

Treatment instituted according to FIRM-ACT protocol (Fassnacht et al. 2012)

ECOG, Eastern Cooperative Oncology Group.

resection can be difficult to determine due to the often close anatomical relationship between tumour capsule and adjacent organs such as the liver or kidney. As a consequence, in some cases the largest possible margin consists of tumour capsule only, which may be only a few cell layers thick. Secondly, the necessity of lymph node dissection (LND) and subsequent resection has not yet been established. It has been suggested in (few) retrospective studies that locoregional LND is associated with improved survival (Reibetanz et al. 2012, Erdogan et al. 2013, Tran et al. 2013). In contrast, a study from the SEER database could not confirm a survival benefit after LND (Saade et al. 2015). Results are difficult to interpret since it remains unknown whether presumed LNDs were performed intentionally and, the other way around, whether pathologists recognized and/or described lymph nodes that in fact were intentionally dissected. Also, the anatomical extent of LND for adrenal tumours is not standardized. Reibetanz et al. (2012) presented a proposal for the field of LND on a sound theoretical basis, but this has not yet been tested in clinical practice. The only way to settle this debate is to perform a prospective randomized trial with standardized surgical technique, but this seems difficult in such a rare disease. A third subject of debate is the surgical approach, i.e., laparoscopy or laparotomy. A minimally invasive technique is supposed to offer shortterm benefits such as lower morbidity and shorter hospital stay (Brix et al. 2010, Porpiglia et al. 2010, Lombardi et al. 2012, Donatini et al. 2014). Those in favour of laparotomy advocate that this approach holds a lower risk of tumour rupture (Miller et al. 2010, 2012, Cooper et al. 2013, Mir et al. 2013, Toniato 2013). It is expected that individual preferences and skills are highly influential on the outcome. A literature review of 23 retrospective studies

Published by Bioscientifica Ltd. 
addressing this question concluded that open surgery should remain the default option in ACC (Jurowich et al. 2013). However, in case of limited size tumours $(<10 \mathrm{~cm})$, radical resection through a laparoscopic approach should be technically feasible if performed by an experienced surgeon. If there is evidence of invasive disease, laparotomy should be performed as extensive resection might be necessary.

In selected patients presenting with metastasized disease, debulking surgery might yield a survival benefit (Kerkhofs et al. 2013b, Dy et al. 2015). Prospective studies on this topic are not yet available, and retrospective studies inevitably hold selection bias: chances are that patients who underwent debulking surgery were in better clinical condition compared to patients who were not operated on. Patients with metachronous oligometastases might benefit from local surgical resection or other local ablative measures. Evidence is limited and these interventions are probably best applicable to patients with otherwise favourable prognostic characteristics (Wood et al. 2003, Cazejust et al. 2010, Baudin et al. 2011). In recurrent (local) disease, surgery is the treatment of choice. Main predictors of outcome in this situation are time to first recurrence and resectability of the recurred tumour (Erdogan et al. 2013). Patients with a time to recurrence longer than 1 year and a completely resected recurrence have the best prognosis. In patients with early and/or not completely resectable recurrence, surgical treatment may be considered.

\section{Mitotane}

Drug therapy with mitotane has been in use since 1959 for the treatment of patients with irresectable or metastasized ACC (Bergenstal et al. 1960, Lubitz et al. 1973, Baudin et al. 2011, Fassnacht et al. 2011). Mitotane is derived from the insecticide dichlorodiphenyltrichloroethane (DDT) and is administered orally in tablets in two to three daily doses. The drug exerts an anti-neoplastic effect on ACC tissue and in addition inhibits cortisol synthesis, which is beneficial in patients with Cushing's syndrome (Southren et al. 1966, Fukushima et al. 1971, Touitou et al. 1978, Ghataore et al. 2012). The antineoplastic effect is correlated with the plasma level of mitotane. A therapeutic response was observed in patients with plasma levels $>14 \mathrm{mg} / \mathrm{l}$, which is therefore considered as the lower limit of the therapeutic window (Haak et al. 1994, Baudin et al. 2001). Mitotane is well known for its toxicity, in particular for the gastrointestinal tract (nausea, diarrhoea, vomiting) and the nervous system (ataxia, amnesia, confusion) (Daffara et al. 2008). Toxicity of mitotane appears to be correlated with its plasma concentration, which is why a plasma level of $20 \mathrm{mg} / \mathrm{l}$ is considered the upper limit of the therapeutic window (Baudin et al. 2001). Patients (and their physicians) intuitively want to achieve therapeutic mitotane concentrations as early as possible in order to rapidly establish antiproliferative efficacy. A problematic aspect is that the drug's half-life is quite variable between patients but is in general extremely long (13-159 days) (Moolenaar et al. 1981). Therefore, it takes a very long time (on average 3 months) to reach the therapeutic level between 14 and $20 \mathrm{mg} / \mathrm{l}$ (Terzolo et al. 2000, Faggiano et al. 2006, Kerkhofs et al. 2013c). Especially in patients presenting with stage IV disease $( \pm 50 \%$ of patients), this long build-up phase delays effective treatment. Also, co-administration of chemotherapy might affect mitotane pharmacokinetics by inducing or inhibiting enzymes involved in drug metabolism (Kerkhofs et al. 2013c). Pharmacokinetic studies demonstrated that mitotane concentrations in fatty tissue are $\sim 200$-fold higher than in plasma and drug distribution appears to be far more important than drug elimination (von Slooten et al. 1982). Currently, research is focused at optimizing dosing schedules with help of therapeutic drug monitoring and pharmacogenetics (D'Avolio et al. 2013, Kerkhofs et al. 2015b). The aim is to shorten the plasma level build-up time and to minimize drug toxicity. For example, in patients presenting with stage IV disease not amenable to surgical resection, shortterm achievement of adequate mitotane monotherapy may postpone the necessity of the often toxic and invalidating etoposide/doxorubicin/cisplatin (EDP) chemotherapy. On a side note, EDP chemotherapy may be more effective in combination with adequate mitotane levels due to an interaction at the drug-resistance protein, which is an additional argument to optimize mitotane treatment first (Bates et al. 1991, Berruti et al. 1998).

In addition to the established application of mitotane in patients with advanced disease, mitotane is increasingly being used as adjuvant treatment after complete resection. This is based on convincing retrospective evidence suggesting prolonged recurrence-free and overall survival (Terzolo et al. 2007). According to the 2012 ESMO guidelines, adjuvant mitotane is recommended in patients with a high risk of disease recurrence defined by stage III disease, Ki-67 $>10 \%$, or incomplete resection (Berruti et al. 2012a). Adjuvant treatment with mitotane is prospectively compared in a randomized trial that is currently recruiting patients with stage I-III disease who underwent a complete resection and had a Ki-67 $<10 \%$ (Efficacy of Adjuvant Mitotane Treatment in Prolonging

Published by Bioscientifica Ltd. 
Recurrence-free Survival in Patients With Adrenocortical Carcinoma at Low-intermediate Risk of Recurrence (ADIUVO-trial), NCT00777244).

In this era of targeted therapy and drug engineering, it may seem unwise to rely on an old and toxic drug. However, no modern drug has yet proven to be effective and possible new agents will have to be compared to mitotane first. Since mitotane is currently the only effective drug available, it will remain the backbone of medical therapy in ACC during the following years. Figure 3 contains a comprehensive flowchart of mitotane clinical management based on available literature and personal experience. It is important to realize that despite optimization of dosing schedules, the key factor influencing build-up of mitotane plasma levels is patient tolerability. From this perspective, the importance of adequate supportive treatment cannot be stressed enough, i.e., administration of hydrocortisone, anti-emetic and anti-diarrheal drugs if necessary. The strong CYP3A4 induction by mitotane necessitates careful selection of supportive drugs (van Erp et al. 2011, Kroiss et al. 2011). A possible strategy is to start concomitant treatment on day 1 including hydrocortisone $20 \mathrm{mg}$, metoclopramide $10 \mathrm{mg}$ two times daily (as needed) and loperamide $2 \mathrm{mg}$ two to four times daily (as needed). Hydrocortisone should be administered in supraphysiological doses because of CYP3A4 induction, which increases glucocorticoid metabolism (Chortis et al. 2013). Frequent assessment (every 3 months) of thyroid hormone status is necessary as mitotane may induce a clinical picture similar to central hypothyroidism, possibly through a direct effect on the pituitary gland or induction of thyroid hormone metabolism (Zatelli et al. 2010). Based on clinical experience, treatment with thyroxine supplementation restores

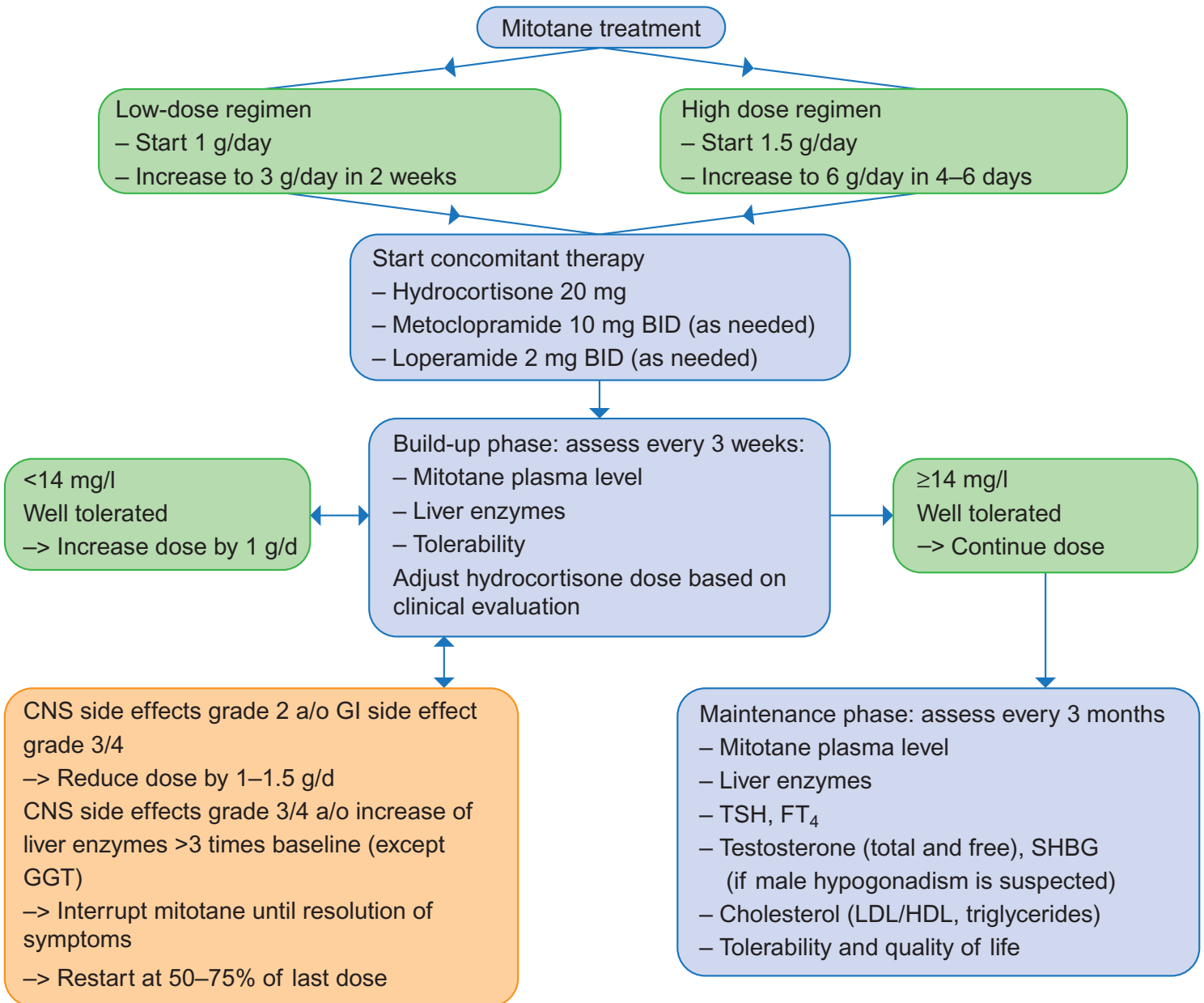

Figure 3

Flowchart of clinical management in starting and maintaining mitotane treatment. Gl, gastro-intestinal; grading of side effects according to National Cancer Institute Common Terminology Criteria for Adverse Events (NCl-CTCAE) version 4; GGT, gamma-glutamyltransferase. 
euthyroidism. In men with signs of hypogonadism, assessment of testosterone and sex hormone-binding globulin levels is warranted, as (yet unexplained) disturbances in mitotane treated patients are common (Berruti et al. 2012a). Since mitotane inhibits $5 \alpha$-reductase, the enzyme that converts testosterone in the more potent metabolite $5 \alpha$-dihydrotestosterone, treatment with testosterone supplementation may be ineffective. Supplementation of synthetic dihydrotestosterone should have the desired effect. Another (presumed) consequence of $5 \alpha$ inhibition is increased conversion of testosterone to $17 \beta$-estradiol, which could explain the occurrence of gynecomastia in mitotane-treated men (Daffara et al. 2008, Chortis et al. 2013). Psychological and social aspects of treatment should not be neglected, i.e., professional counselling may be warranted. Follow-up on patient's well-being may be performed by questionnaire-based assessment of toxicity upon the start of the treatment and by repeating this assessment every 3 months. This facilitates early recognition and optimization of supportive treatment and, if necessary, mitotane dose adjustments. In our experience educating patients about side effects, taking the time to register side effects and providing instruments to alleviate them improves compliance and patient motivation to stay on treatment.

\section{Chemotherapy}

One of the greatest achievements in ACC research was the completion of the FIRM-ACT trial, which established the regimen EDP combined with mitotane as first-line chemotherapy in advanced ACC. An objective response was achieved in 23\% of patients (Fassnacht et al. 2012). The secondary endpoint was defined as progression free survival at 8 weeks, which was achieved in $58 \%$ of patients. The question could be asked whether a three-drug regimen is necessary to achieve these results. Therefore, a noninferiority trial seems justified. On the other hand, given the overall poor prognosis in this group, it may be wiser to deploy available resources to a trial comparing new drugs to the existing regimen of EDP. It is problematic that no other regimens of cytotoxic drugs demonstrated results that even approximate those of EDP. Based on the results of a phase II trial, a combined regimen of gemcitabine/ capecitabine is now offered as second-line therapy in Dutch and German expert centres. This regimen resulted in disease control during 6 months in $29 \%$ of 28 patients (Sperone et al. 2010). Other studies including cytotoxic chemotherapy only produced disappointing results. Among the tested agents were capecitabine (combined with bevacizumab) (Wortmann et al. 2010), paclitaxel (Berruti et al. 2012b), irinotecan (Baudin et al. 2002) and docetaxel (combined with cisplatin) (Urup et al. 2013). Again, mitotane is a hindrance in investigating new drugs, since virtually all patients in advanced stages are pre-treated.

\section{Radiotherapy}

The application of adjuvant radiotherapy in ACC has so far only been studied in retrospective setting (Fassnacht et al. 2006, Sabolch et al. 2011, Habra et al. 2013). None of these studies demonstrated a benefit in disease-free or overall survival after adjuvant radiotherapy, whereas two studies did report a beneficial effect on the local recurrence rate (Fassnacht et al. 2006, Sabolch et al. 2011). Since local recurrence does not seem to be the most important predictor of survival, it is expected that systemic adjuvant therapy is more important than local control.

In a different setting, i.e., after incomplete surgical resection, radiotherapy in combination with mitotane is recommended (Berruti et al. 2012a). The rationale behind this recommendation is that patients with residual disease after surgery perform worse compared to patients who had a complete resection and aggressive treatment is warranted (Libe et al. 2015). Polat et al. (2009) suggested a dosing regimen based on clinical experience consisting of a total dose $>40$ Gy with single fractions of $1.8-2 \mathrm{~Gy}$. This includes a boost volume to reach 50-60 Gy in individual patients. As discussed above, there is a subgroup of ACC patients with indolent disease, for example with slowly progressive oligometastases in $\leq 2$ organs. Based on personal clinical experience, we believe these patients might benefit from stereotactic body radiation therapy. This technique is continuously being refined and deserves further study as it holds the potential of prolonging local control in patients with often limited tumour load, in whom toxic systemic therapy would otherwise be the only option (Salama \& Milano 2014). Another new technique in patients with metastasized disease is treatment with radioactive isotopes. A treatment protocol based on the radionuclide $\left[{ }^{131} \mathrm{I}\right]$ iodometomidate (IMTO) has been tested on 11 patients and resulted in a partial response in one patient and stable disease in five patients (Hahner et al. 2012). Further research will have to prove the potential of this promising treatment modality. Radiotherapy with palliative intent, for example irradiation of painful bone metastases or a large irresectable primary tumour, is widely accepted as a considerably effective measure. Evidence is again retrospective and mostly based

Published by Bioscientifica Ltd. 
on single-institution experience (Polat et al. 2009, Hermsen et al. 2010, Ho et al. 2013).

\section{Targeted therapy}

Several targeted therapies have been tested in mostly small-scale trials; none of these has yet earned a place in the treatment algorithm. Among the targets examined in case series were the platelet-derived growth factor receptor (PDGFR-R) and stem cell ligand receptor (Gross et al. 2006); epidermal growth factor receptor (EGFR) (Quinkler et al. 2008); vascular endothelial growth factor (VEGF) (Wortmann et al. 2010) and the mammalian target of rapamycin (mTOR) pathway (Fraenkel et al. 2013). An expanded phase I study combined the IGF1R inhibitor cixutumumab and the mTOR inhibitor temsirolimus in 26 patients. Two phase II trials examined the efficacy of multi-tyrosine kinase inhibitors sorafenib and sunitinib in ten and 38 patients respectively (Berruti et al. 2012b, Kroiss et al. 2012). In general, these studies demonstrated disappointing results without any objective response and with only a few patients experiencing a short-lived stabilization of their disease. So far, the only phase III trial involving a targeted treatment is a study on the IGF1R inhibitor linsitinib (Fassnacht et al. 2015). A confirmed partial response was observed in three patients, but in the total population there was no increase in overall or progression-free survival. Interpretation of results from trials with targeted therapies is difficult for several reasons. In the first place, most patients who participated in these studies were pre-treated with mitotane and chemotherapy and were in advanced stage of their disease. It is likely that these tumours became drug-resistant and were hardly responsive to any therapy, or not responsive at all. Secondly, pre-treatment with mitotane and consequently CYP3A4 induction might have impaired the effectiveness of the therapies studied. This is a problematic aspect of mitotane treatment, especially since the half-life is so long and mitotane remains detectable in plasma months after cessation of treatment. It is unknown how long it takes for the inductive effect to wear off. As a result, timing of targeted therapies in clinical management (or trial participation for that matter) is difficult to determine. It seems logical to test potential new drugs in a setting where they can be compared to mitotane. Patients with advanced ACC (modified ENSAT stage IV-A) who had no prior systemic therapy and who would qualify for treatment with mitotane monotherapy (possibly after debulking surgery) could form the most suitable subgroup for such a trial. Thirdly, recent research made it increasingly clear that there is a subgroup of patients with metastatic disease and an indolent course of disease (Assie et al. 2014). It is not inconceivable that their natural course of disease resembles stable disease for several months while on a study drug. In future studies patients should be meticulously stratified, not only based on tumour characteristics but also based on disease progression in months or even years before participation.

Research on immunotherapy in adrenocortical carcinoma is still at a preliminary stage. Blocking the programmed death-1 (PD-1) or programmed death-ligand 1 (PD-L1) receptor in an attempt to direct a T-cell response to tumour tissue has been successful in renal cell carcinoma, melanoma and non-small cell lung carcinoma (Topalian et al. 2012). Exploratory research on a small scale $(n=28)$ demonstrated ACC may express PD-L1 on the cell surface (Fay et al. 2015). A phase I study with the PD-L1 inhibitor avelumab is currently recruiting and is open to ACC patients (NCT01772004). Other data demonstrated high expression of the survivin protein in a cohort of 29 ACCs, associated with a trend towards poor prognosis (Sbiera et al. 2013). These findings suggest survivin might be a target for immunotherapy, but this has not yet lead to a clinical trial.

\section{Research}

As discussed, there are many clinical questions yet unanswered and many trials to be performed. The ENSAT is an expanding collaboration formed by researchers and clinicians. It holds a database with clinical data of $>2200$ ACC patients (as of June 2015), which is of great potential for future studies. Collection of biomaterial such as blood, urine and tumour samples is important in order to facilitate research. Due to high costs associated with genomic research projects in particular, up-scaling to European or even global platforms seems necessary to be able to fund these undertakings. National laws on the use of archival tumour tissue may differ. It is recommended to consult the local ethics committee on prevailing regulations regarding the establishment of a local biobank. A starting point should be to obtain informed consent from the patient for future (genomic) research on tumour tissue before surgery, even if the exact content of said research is not specified. International networks could facilitate this by supplying standard consent forms, issue standard operating procedures for tissue handling or even sponsor a central storage facility. In addition, international networks should promote development of international standards for reporting surgery and

Published by Bioscientifica Ltd. 
pathology results, determination of the Ki-67 index and USP cut-off values.

\section{Conclusion}

The present review discusses current and future ACC diagnostics, prognostics and treatment concepts. In addition, it provides a view on organization of care and international collaboration. In the near future, we expect USP to gain a place in daily practice diagnostics of adrenal tumours. Application in follow-up of ACC patients is promising but needs additional research. A recent proposal for refinement of the most important clinical prognostic factor, stage of disease, is expected to become standard practice. Currently, the best indicator of recurrence-free and overall survival is determination of the proliferation marker Ki-67. This technique needs standardization, since it will take several years before its successor, genomic profiling, will be ready for clinical practice. Risk stratification is needed to select patients for adjuvant treatment, since complete surgical resection alone, with or without LND, cannot guarantee recurrence-free survival. Mitotane will remain the backbone of drug therapy in years to come. Its tolerability and long plasma level buildup phase may be improved by therapeutic drug monitoring based on pharmacokinetic modelling and intensive counselling of patients. Due to the rarity of disease, it is questionable whether expert centres should be instituted based on volume requirements. We advocate the treatment of patients in centres with established experience in multidisciplinary oncologic care, that adhere to prevailing guidelines and state-of-the-art in diagnostic and treatment concepts. International collaboration is necessary to facilitate fundamental research and clinical trials to test new treatment possibilities that are so badly needed.

\section{Declaration of interest}

The authors declare that there is no conflict of interest that could be perceived as prejudicing the impartiality of the review.

\section{Funding}

This review did not receive any specific grant from any funding agency in the public, commercial or not-for-profit sector.

\section{References}

Abiven G, Coste J, Groussin L, Anract P, Tissier F, Legmann P, Dousset B, Bertagna X \& Bertherat J 2006 Clinical and biological features in the prognosis of adrenocortical cancer: poor outcome of cortisol-secreting tumors in a series of 202 consecutive patients. Journal of Clinical Endocrinology and Metabolism 91 2650-2655. (doi:10.1210/ jc.2005-2730)

Arlt W, Biehl M, Taylor AE, Hahner S, Libe R, Hughes BA, Schneider P, Smith DJ, Stiekema H, Krone N et al. 2011 Urine steroid metabolomics as a biomarker tool for detecting malignancy in adrenal tumors. Journal of Clinical Endocrinology and Metabolism 96 3775-3784. (doi:10.1210/jc.2011-1565)

Assie G, Antoni G, Tissier F, Caillou B, Abiven G, Gicquel C, Leboulleux S, Travagli JP, Dromain C, Bertagna X et al. 2007 Prognostic parameters of metastatic adrenocortical carcinoma. Journal of Clinical Endocrinology and Metabolism 92 148-154. (doi:10.1210/jc.2006-0706)

Assie G, Letouze E, Fassnacht M, Jouinot A, Luscap W, Barreau O, Omeiri H, Rodriguez S, Perlemoine K, Rene-Corail F et al. 2014 Integrated genomic characterization of adrenocortical carcinoma. Nature Genetics 46 607-612. (doi:10.1038/ng.2953)

Barreau O, Assie G, Wilmot-Roussel H, Ragazzon B, Baudry C, Perlemoine K, Rene-Corail F, Bertagna X, Dousset B, Hamzaoui N et al. 2013 Identification of a CpG island methylator phenotype in adrenocortical carcinomas. Journal of Clinical Endocrinology and Metabolism 98 E174-E184. (doi:10.1210/jc.2012-2993)

Bates SE, Shieh CY, Mickley LA, Dichek HL, Gazdar A, Loriaux DL \& Fojo AT 1991 Mitotane enhances cytotoxicity of chemotherapy in cell lines expressing a multidrug resistance gene (mdr-1/P-glycoprotein) which is also expressed by adrenocortical carcinomas. Journal of Clinical Endocrinology and Metabolism 73 18-29. (doi:10.1210/ jcem-73-1-18)

Baudin E, Pellegriti G, Bonnay M, Penfornis A, Laplanche A, Vassal G \& Schlumberger M 2001 Impact of monitoring plasma 1,1-dichlorodiphenildichloroethane (o,p'DDD) levels on the treatment of patients with adrenocortical carcinoma. Cancer 92 1385-1392. (doi:10.1002/ 1097-0142(20010915)92:6<1385::AID-CNCR1461>3.0.CO;2-2)

Baudin E, Docao C, Gicquel C, Vassal G, Bachelot A, Penfornis A \& Schlumberger M 2002 Use of a topoisomerase I inhibitor (irinotecan, CPT-11) in metastatic adrenocortical carcinoma. Annals of Oncology $\mathbf{1 3}$ 1806-1809. (doi:10.1093/annonc/mdf291)

Baudin E, Leboulleux S, Al Ghuzlan A, Chougnet C, Young J, Deandreis D, Dumont F, Dechamps F, Caramella C, Chanson P et al. 2011 Therapeutic management of advanced adrenocortical carcinoma: what do we know in 2011? Hormones \& Cancer 2 363-371. (doi:10.1007/ s12672-011-0094-2)

Bergenstal D, Hertz R, Lipsett M \& Moy R 1960 Chemotherapy of adrenocortical cancer with o, $\mathrm{p}^{\prime}$-DDD. Annals of Internal Medicine $\mathbf{5 3}$ 672. (doi:10.7326/0003-4819-53-4-672)

Berruti A, Terzolo M, Pia A, Angeli A \& Dogliotti L 1998 Mitotane associated with etoposide, doxorubicin, and cisplatin in the treatment of advanced adrenocortical carcinoma. Italian Group for the Study of Adrenal Cancer. Cancer 83 2194-2200. (doi:10.1002/(SICI)1097-0142 (19981115)83:10<2194::AID-CNCR19>3.3.CO;2-V)

Berruti A, Terzolo M, Sperone P, Pia A, Casa SD, Gross DJ, Carnaghi C, Casali P, Porpiglia F, Mantero F et al. 2005 Etoposide, doxorubicin and cisplatin plus mitotane in the treatment of advanced adrenocortical carcinoma: a large prospective phase II trial. Endocrine-Related Cancer 12 657-666. (doi:10.1677/erc.1.01025)

Berruti A, Baudin E, Gelderblom H, Haak HR, Porpiglia F, Fassnacht M, Pentheroudakis $\mathrm{G} \&$ On behalf of the ESMO Guidelines Working Group 2012a Adrenal cancer: ESMO Clinical Practice Guidelines for diagnosis, treatment and follow-up. Annals of Oncology 23 vii131-vii138. (doi:10.1093/annonc/mds231)

Berruti A, Sperone P, Ferrero A, Germano A, Ardito A, Priola AM, De Francia S, Volante M, Daffara F, Generali D et al. 2012b Phase II study of weekly paclitaxel and sorafenib as second/third line therapy in patients with adrenocortical carcinoma. European Journal of Endocrinology 166 451-458. (doi:10.1530/EJE-11-0918) 
Berruti A, Fassnacht M, Haak H, Else T, Baudin E, Sperone P, Kroiss M, Kerkhofs T, Williams AR, Ardito A et al. 2014 Prognostic role of overt hypercortisolism in completely operated patients with adrenocortical cancer. European Urology 65 832-838. (doi:10.1016/j.eururo.2013. 11.006)

Beuschlein F, Weigel J, Saeger W, Kroiss M, Wild V, Daffara F, Libe R, Ardito A, Al Ghuzlan A, Quinkler M et al. 2015 Major prognostic role of Ki67 in localized adrenocortical carcinoma after complete resection. Journal of Clinical Endocrinology and Metabolism 100 841-849. (doi:10.1210/jc.2014-3182)

Brix D, Allolio B, Fenske W, Agha A, Dralle H, Jurowich C, Langer P, Mussack T, Nies C, Riedmiller H et al. 2010 Laparoscopic versus open adrenalectomy for adrenocortical carcinoma: surgical and oncologic outcome in 152 patients. European Urology 58 609-615. (doi:10.1016/ j.eururo.2010.06.024)

Cazejust J, De Baere T, Auperin A, Deschamps F, Hechelhammer L, Abdel-Rehim M, Schlumberger M, Leboulleux S \& Baudin E 2010 Transcatheter arterial chemoembolization for liver metastases in patients with adrenocortical carcinoma. Journal of Vascular and Interventional Radiology 21 1527-1532. (doi:10.1016/j.jvir.2010.05.020)

Chabre O, Libe R, Assie G, Barreau O, Bertherat J, Bertagna X, Feige JJ \& Cherradi N 2013 Serum miR-483-5p and miR-195 are predictive of recurrence risk in adrenocortical cancer patients. Endocrine-Related Cancer 20 579-594. (doi:10.1530/ERC-13-0051)

Chortis V, Taylor AE, Schneider P, Tomlinson JW, Hughes BA, O'Neil DM, Libe R, Allolio B, Bertagna X, Bertherat J et al. 2013 Mitotane therapy in adrenocortical cancer induces CYP3A4 and inhibits $5 \alpha$-reductase, explaining the need for personalized glucocorticoid and androgen replacement. Journal of Clinical Endocrinology and Metabolism 98 161-171. (doi:10.1210/jc.2012-2851)

Cooper AB, Habra MA, Grubbs EG, Bednarski BK, Ying AK, Perrier ND, Lee JE \& Aloia TA 2013 Does laparoscopic adrenalectomy jeopardize oncologic outcomes for patients with adrenocortical carcinoma? Surgical Endoscopy 27 4026-4032. (doi:10.1007/s00464-013-3034-0)

Daffara F, De Francia S, Reimondo G, Zaggia B, Aroasio E, Porpiglia F, Volante M, Termine A, Di Carlo F, Dogliotti L et al. 2008 Prospective evaluation of mitotane toxicity in adrenocortical cancer patients treated adjuvantly. Endocrine-Related Cancer 15 1043-1053. (doi:10.1677/ERC-08-0103)

D'Avolio A, De Francia S, Basile V, Cusato J, De Martino F, Pirro E, Piccione F, Ardito A, Zaggia B, Volante M et al. 2013 Influence of the CYP2B6 polymorphism on the pharmacokinetics of mitotane. Pharmacogenetics and Genomics 23 293-300. (doi:10.1097/FPC. Ob013e3283606cb2)

De Reynies A, Assie G, Rickman DS, Tissier F, Groussin L, Rene-Corail F, Dousset B, Bertagna X, Clauser E \& Bertherat J 2009 Gene expression profiling reveals a new classification of adrenocortical tumors and identifies molecular predictors of malignancy and survival. Journal of Clinical Oncology 27 1108-1115. (doi:10.1200/JCO.2008.18.5678)

Donatini G, Caiazzo R, Do Cao C, Aubert S, Zerrweck C, El-Kathib Z, Gauthier T, Leteurtre E, Wemeau JL, Vantyghem MC et al. 2014 Long-term survival after adrenalectomy for stage I/II adrenocortical carcinoma (ACC): a retrospective comparative cohort study of laparoscopic versus open approach. Annals of Surgical Oncology 21 284-291. (doi:10.1245/s10434-013-3164-6)

Dy BM, Strajina V, Cayo AK, Richards ML, Farley DR, Grant CS, Harmsen WS, Evans DB, Grubbs EG, Bible KC et al. 2015 Surgical resection of synchronously metastatic adrenocortical cancer. Annals of Surgical Oncology 22 146-151. (doi:10.1245/s10434-014-3944-7)

Erdogan I, Deutschbein T, Jurowich C, Kroiss M, Ronchi C, Quinkler M, Waldmann J, Willenberg HS, Beuschlein F, Fottner C et al. 2013 The role of surgery in the management of recurrent adrenocortical carcinoma. Journal of Clinical Endocrinology and Metabolism 98 181-191. (doi:10.1210/jc.2012-2559)

van Erp NP, Guchelaar HJ, Ploeger BA, Romijn JA, Hartigh J \& Gelderblom H 2011 Mitotane has a strong and a durable inducing effect on CYP3A4 activity. European Journal of Endocrinology 164 621-626. (doi:10.1530/EJE-10-0956)

Faggiano A, Leboulleux S, Young J, Schlumberger M \& Baudin E 2006 Rapidly progressing high o,p'DDD doses shorten the time required to reach the therapeutic threshold with an acceptable tolerance: preliminary results. Clinical Endocrinology 64 110-113. (doi:10.1111/ j.1365-2265.2005.02403.x)

Fassnacht M \& Allolio B 2009 Clinical management of adrenocortical carcinoma. Best Practice \& Research. Clinical Endocrinology \& Metabolism 23 273-289. (doi:10.1016/j.beem.2008.10.008)

Fassnacht M, Hahner S, Polat B, Koschker AC, Kenn W, Flentje M \& Allolio B 2006 Efficacy of adjuvant radiotherapy of the tumor bed on local recurrence of adrenocortical carcinoma. Journal of Clinical Endocrinology and Metabolism 91 4501-4504. (doi:10.1210/jc.20061007)

Fassnacht M, Johanssen S, Quinkler M, Bucsky P, Willenberg HS, Beuschlein F, Terzolo M, Mueller HH, Hahner S, Allolio B et al. 2009 Limited prognostic value of the 2004 International Union Against Cancer staging classification for adrenocortical carcinoma: proposal for a Revised TNM Classification. Cancer 115 243-250. (doi:10.1002/cncr. 24030)

Fassnacht M, Johanssen S, Fenske W, Weismann D, Agha A, Beuschlein F, Fuhrer D, Jurowich C, Quinkler M, Petersenn S et al. 2010 Improved survival in patients with stage II adrenocortical carcinoma followed up prospectively by specialized centers. Journal of Clinical Endocrinology and Metabolism 95 4925-4932. (doi:10.1210/jc.2010-0803)

Fassnacht M, Libe R, Kroiss M \& Allolio B 2011 Adrenocortical carcinoma: a clinician's update. Nature Reviews. Endocrinology 7 323-335. (doi:10.1038/nrendo.2010.235)

Fassnacht M, Terzolo M, Allolio B, Baudin E, Haak H, Berruti A, Welin S, Schade-Brittinger C, Lacroix A, Jarzab B et al. 2012 Combination chemotherapy in advanced adrenocortical carcinoma. New England Journal of Medicine 366 2189-2197. (doi:10.1056/NEJMoa1200966)

Fassnacht M, Berruti A, Baudin E, Demeure MJ, Gilbert J, Haak H, Kroiss M, Quinn DI, Hesseltine E, Ronchi CL et al. 2015 Linsitinib (OSI-906) versus placebo for patients with locally advanced or metastatic adrenocortical carcinoma: a double-blind, randomised, phase 3 study. Lancet. Oncology 16 426-435. (doi:10.1016/S1470-2045(15)70081-1)

Fay AP, Signoretti S, Callea M, Telomicron GH, McKay RR, Song J, Carvo I, Lampron ME, Kaymakcalan MD, Poli-de-Figueiredo CE et al. 2015 Programmed death ligand-1 expression in adrenocortical carcinoma: an exploratory biomarker study. Journal for Immunotherapy of Cancer 33. (doi:10.1186/s40425-015-0047-3)

Finks JF, Osborne NH \& Birkmeyer JD 2011 Trends in hospital volume and operative mortality for high-risk surgery. New England Journal of Medicine 364 2128-2137. (doi:10.1056/NEJMsa1010705)

Fraenkel M, Gueorguiev M, Barak D, Salmon A, Grossman AB \& Gross DJ 2013 Everolimus therapy for progressive adrenocortical cancer. Endocrine 44 187-192. (doi:10.1007/s12020-013-9878-1)

Fukushima DK, Bradlow HL \& Hellman L 1971 Effects of o,p'-DDD on cortisol and 6- $\beta$-hydroxycortisol secretion and metabolism in man. Journal of Clinical Endocrinology and Metabolism 32 192-200. (doi:10.1210/jcem-32-2-192)

Ghataore L, Chakraborti I, Aylwin SJ, Schulte KM, Dworakowska D, Coskeran P \& Taylor NF 2012 Effects of mitotane treatment on human steroid metabolism: implications for patient management. Endocrine Connections 1 37-47. (doi:10.1530/EC-12-0028)

Giordano TJ, Kuick R, Else T, Gauger PG, Vinco M, Bauersfeld J, Sanders D, Thomas DG, Doherty G \& Hammer G 2009 Molecular classification and prognostication of adrenocortical tumors by transcriptome profiling. Clinical Cancer Research 15 668-676. (doi:10.1158/1078-0432. CCR-08-1067)

Gross DJ, Munter G, Bitan M, Siegal T, Gabizon A, Weitzen R, Merimsky O, Ackerstein A, Salmon A, Sella A et al. 2006 The role of imatinib mesylate (Glivec) for treatment of patients with malignant endocrine tumors 
positive for c-kit or PDGF-R. Endocrine-Related Cancer 13 535-540. (doi:10.1677/erc.1.01124)

Grubbs EG, Callender GG, Xing Y, Perrier ND, Evans DB, Phan AT \& Lee JE 2010 Recurrence of adrenal cortical carcinoma following resection: surgery alone can achieve results equal to surgery plus mitotane. Annals of Surgical Oncology 17 263-270. (doi:10.1245/s10434-009-0716-x)

Haak HR, Hermans J, van de Velde CJ, Lentjes EG, Goslings BM, Fleuren GJ \& Krans HM 1994 Optimal treatment of adrenocortical carcinoma with mitotane: results in a consecutive series of 96 patients. British Journal of Cancer 69 947-951. (doi:10.1038/bjc.1994.183)

Habra MA, Ejaz S, Feng L, Das P, Deniz F, Grubbs EG, Phan A, Waguespack SG, Ayala-Ramirez M, Jimenez C et al. 2013 A retrospective cohort analysis of the efficacy of adjuvant radiotherapy after primary surgical resection in patients with adrenocortical carcinoma. Journal of Clinical Endocrinology and Metabolism 98 192-197. (doi:10.1210/jc.2012-2367)

Hahner S, Kreissl MC, Fassnacht M, Haenscheid H, Knoedler P, Lang K, Buck AK, Reiners C, Allolio B \& Schirbel A 2012 [ ${ }^{131}$ I] iodometomidate for targeted radionuclide therapy of advanced adrenocortical carcinoma. Journal of Clinical Endocrinology and Metabolism 97 914-922. (doi:10.1210/jc.2011-2765)

Hermsen IG, Gelderblom H, Kievit J, Romijn JA \& Haak HR 2008 Extremely long survival in six patients despite recurrent and metastatic adrenal carcinoma. European Journal of Endocrinology 158 911-919. (doi:10.1530/EJE-07-0723)

Hermsen IG, Groenen YE, Dercksen MW, Theuws J \& Haak HR 2010 Response to radiation therapy in adrenocortical carcinoma. Journal of Endocrinological Investigation 33 712-714. (doi:10.1007/BF03346675)

Hermsen IG, Kerkhofs TM, Butter G, Kievit J, van Eijck CH, Nieveen van Dijkum EJ, Haak HR \& Dutch Adrenal Network 2012 Surgery in adrenocortical carcinoma: importance of national cooperation and centralized surgery. Surgery 152 50-56. (doi:10.1016/j.surg.2012.02.005)

Ho V, de Raaf A, van der Hoeven K \& Jansen-Landheer M 2013 IKNL berekent effect volumenormen op ziekenhuizen en patiënten. Medisch Contact $134-37$.

Ho J, Turkbey B, Edgerly M, Alimchandani M, Quezado M, Camphausen K, Fojo T \& Kaushal A 2013 Role of radiotherapy in adrenocortical carcinoma. Cancer Journal 19 288-294. (doi:10.1097/PPO. Ob013e31829e3221)

Jurowich C, Fassnacht M, Kroiss M, Deutschbein T, Germer CT \& Reibetanz J 2013 Is there a role for laparoscopic adrenalectomy in patients with suspected adrenocortical carcinoma? A critical appraisal of the literature Hormone and Metabolic Research 45 130-136. (doi:10.1055/s-0032-1331743)

Kebebew E, Reiff E, Duh QY, Clark OH \& McMillan A 2006 Extent of disease at presentation and outcome for adrenocortical carcinoma: have we made progress? World Journal of Surgery $\mathbf{3 0} 872-878$. (doi:10.1007/ s00268-005-0329-x)

Kerkhofs TM, Verhoeven RH, Van der Zwan JM, Dieleman J, Kerstens MN, Links TP, Van de Poll-Franse LV \& Haak HR 2013a Adrenocortical carcinoma: a population-based study on incidence and survival in The Netherlands since 1993. European Journal of Cancer 49 2579-2586. (doi:10.1016/j.ejca.2013.02.034)

Kerkhofs TM, Verhoeven RH, Bonjer HJ, van Dijkum EJ, Vriens MR, De Vries J, Van Eijck CH, Bonsing BA, Van de Poll-Franse LV, Haak HR et al. $2013 b$ Surgery for adrenocortical carcinoma in The Netherlands: analysis of the national cancer registry data. European Journal of Endocrinology 169 83-89. (doi:10.1530/EJE-13-0142)

Kerkhofs TM, Baudin E, Terzolo M, Allolio B, Chadarevian R, Mueller HH, Skogseid B, Leboulleux S, Mantero F, Haak HR et al. 2013c Comparison of two mitotane starting dose regimens in patients with advanced adrenocortical carcinoma. Journal of Clinical Endocrinology and Metabolism 98 4759-4767. (doi:10.1210/jc.2013-2281)

Kerkhofs TM, Kerstens MN, Kema IP, Willems TP \& Haak HR $2015 a$ Diagnostic value of urinary steroid profiling in the evaluation of adrenal tumors. Hormones \& Cancer 6 168-175. (doi:10.1007/s12672015-0224-3)
Kerkhofs TM, Derijks LJ, Ettaieb H, den Hartigh J, Neef K, Gelderblom H, Guchelaar HJ \& Haak HR 2015b Development of a pharmacokinetic model of mitotane: toward personalized dosing in adrenocortical carcinoma. Therapeutic Drug Monitoring 37 58-65. (doi:10.1097/FTD. 0000000000000102)

Kroiss M, Quinkler M, Lutz WK, Allolio B \& Fassnacht M 2011 Drug interactions with mitotane by induction of CYP3A4 metabolism in the clinical management of adrenocortical carcinoma. Clinical Endocrinology 75 585-591. (doi:10.1111/j.1365-2265.2011.04214.x)

Kroiss M, Quinkler M, Johanssen S, van Erp NP, Lankheet N, Pollinger A, Laubner K, Strasburger CJ, Hahner S, Muller HH et al. 2012 Sunitinib in refractory adrenocortical carcinoma: a phase II, single-arm, open-label trial. Journal of Clinical Endocrinology and Metabolism 97 3495-3503. (doi:10.1210/jc.2012-1419)

Libé R, Borget I, Ronchi CL, Zaggia B, Kroiss M, Kerkhofs T, Bertherat J, Volante M, Quinkler M, Chabre O et al. 2015 Prognostic factors in stage III-IV adrenocortical carcinomas (ACC): an European Network for the Study of Adrenal Tumor (ENSAT) study. Annals of Oncology 26 2119-2125. (doi:10.1093/annonc/mdv329)

Lombardi CP, Raffaelli M, De Crea C, Boniardi M, De Toma G, Marzano LA, Miccoli P, Minni F, Morino M, Pelizzo MR et al. 2012 Open versus endoscopic adrenalectomy in the treatment of localized (stage I/II) adrenocortical carcinoma: results of a multiinstitutional Italian survey. Surgery 152 1158-1164. (doi:10.1016/j.surg.2012.08.014)

Lubitz JA, Freeman L \& Okun R 1973 Mitotane use in inoperable adrenal cortical carcinoma. Journal of the American Medical Association 223 1109-1112. (doi:10.1001/jama.1973.03220100011003)

Lughezzani G, Sun M, Perrotte P, Jeldres C, Alasker A, Isbarn H, Budaus L, Shariat SF, Guazzoni G, Montorsi F et al. 2010 The European Network for the Study of Adrenal Tumors staging system is prognostically superior to the international union against cancer-staging system: a North American validation. European Journal of Cancer 46 713-719. (doi:10.1016/j.ejca.2009.12.007)

McNicol AM, Struthers AL, Nolan CE, Hermans J \& Haak HR 1997 Proliferation in adrenocortical tumors: correlation with clinical outcome and p53 status. Endocrine Pathology 8 29-36. (doi:10.1007/ BF02739705)

Miller BS, Ammori JB, Gauger PG, Broome JT, Hammer GD \& Doherty GM 2010 Laparoscopic resection is inappropriate in patients with known or suspected adrenocortical carcinoma. World Journal of Surgery 34 1380-1385. (doi:10.1007/s00268-010-0532-2)

Miller BS, Gauger PG, Hammer GD \& Doherty GM 2012 Resection of adrenocortical carcinoma is less complete and local recurrence occurs sooner and more often after laparoscopic adrenalectomy than after open adrenalectomy. Surgery 152 1150-1157. (doi:10.1016/j.surg.2012. 08.024)

Mir MC, Klink JC, Guillotreau J, Long JA, Miocinovic R, Kaouk JH, Simmons MN, Klein E, Krishnamurthi V, Campbell SC et al. 2013 Comparative outcomes of laparoscopic and open adrenalectomy for adrenocortical carcinoma: single, high-volume center experience. Annals of Surgical Oncology 20 1456-1461. (doi:10.1245/s10434-0122760-1)

Moolenaar AJ, van Slooten H, van Seters AP \& Smeenk D 1981 Blood levels of $\mathrm{o}, \mathrm{p}^{\prime}$-DDD following administration in various vehicles after a single dose and during long-term treatment. Cancer Chemotherapy and Pharmacology 7 51-54. (doi:10.1007/BF00258213)

Morimoto R, Satoh F, Murakami O, Suzuki T, Abe T, Tanemoto M, Abe M, Uruno A, Ishidoya S, Arai Y et al. 2008 Immunohistochemistry of a proliferation marker Ki67/MIB1 in adrenocortical carcinomas: Ki67/MIB1 labeling index is a predictor for recurrence of adrenocortical carcinomas. Endocrine Journal 55 49-55. (doi:10.1507/ endocrj.K07-079)

Perna V, Taylor NF, Dworakowska D, Schulte KM, Aylwin S, Al-Hashimi F \& Diaz-Cano SJ 2014 Adrenocortical adenomas with regression and myelolipomatous changes: urinary steroid profiling supports a 
distinctive benign neoplasm. Clinical Endocrinology 81 343-349. (doi:10.1111/cen.12458)

Pinzani P, Scatena C, Salvianti F, Corsini E, Canu L, Poli G, Paglierani M, Piccini V, Pazzagli M, Nesi G et al. 2013 Detection of circulating tumor cells in patients with adrenocortical carcinoma: a monocentric preliminary study. Journal of Clinical Endocrinology and Metabolism 98 3731-3738. (doi:10.1210/jc.2013-1396)

Polat B, Fassnacht M, Pfreundner L, Guckenberger M, Bratengeier K, Johanssen S, Kenn W, Hahner S, Allolio B \& Flentje M 2009 Radiotherapy in adrenocortical carcinoma. Cancer 115 2816-2823. (doi:10.1002/cncr.24331)

Porpiglia F, Fiori C, Daffara F, Zaggia B, Bollito E, Volante M, Berruti A \& Terzolo M 2010 Retrospective evaluation of the outcome of open versus laparoscopic adrenalectomy for stage I and II adrenocortical cancer. European Urology 57 873-878. (doi:10.1016/j.eururo.2010. 01.036)

Pucci E, Papathomas TG, Giordano TJ, Lu H, Duregon E, Volante M, Papotti M, Lloyd R, Tischler A \& Nose V 2014 An international Ki-67 reproducibility study in adrenocortical cancer: a multicenter interobserver variation analysis using virtual microscopy. Abstract on 13th scientific meeting of ENS@T, Nice, France.

Quinkler M, Hahner S, Wortmann S, Johanssen S, Adam P, Ritter C, Strasburger C, Allolio B \& Fassnacht M 2008 Treatment of advanced adrenocortical carcinoma with erlotinib plus gemcitabine. Journal of Clinical Endocrinology and Metabolism 93 2057-2062. (doi:10.1210/jc. 2007-2564)

Reibetanz J, Jurowich C, Erdogan I, Nies C, Rayes N, Dralle H, Behrend M, Allolio B, Fassnacht M \& German ACC Study Group 2012 Impact of lymphadenectomy on the oncologic outcome of patients with adrenocortical carcinoma. Annals of Surgery 255 363-369. (doi:10.1097/ SLA.0b013e3182367ac3)

Saade N, Sadler C \& Goldfarb M 2015 Impact of regional lymph node dissection on disease specific survival in adrenal cortical carcinoma. Hormone and Metabolic Research [in press]. (doi:10.1055/s-00351549877)

Sabolch A, Feng M, Griffith K, Hammer G, Doherty G \& Ben-Josef E 2011 Adjuvant and definitive radiotherapy for adrenocortical carcinoma. International Journal of Radiation Oncology, Biology, Physics $\mathbf{8 0}$ 1477-1484. (doi:10.1016/j.ijrobp.2010.04.030)

Salama JK \& Milano MT 2014 Radical irradiation of extracranial oligometastases. Journal of Clinical Oncology 32 2902-2912. (doi:10.1200/JCO.2014.55.9567)

Sasano H, Suzuki T \& Moriya T 2006 Recent advances in histopathology and immunohistochemistry of adrenocortical carcinoma. Endocrine Pathology 17 345-354. (doi:10.1007/s12022-006-0006-0)

Sbiera S, Kroiss M, Thamm T, Beyer M, Majidi F, Kuehner D, Wobser M, Becker JC, Adam P, Ronchi C et al. 2013 Survivin in adrenocortical tumors - pathophysiological implications and therapeutic potential. Hormone and Metabolic Research 45 137-146. (doi:10.1055/s-00321327750)

Schulick RD \& Brennan MF 1999 Long-term survival after complete resection and repeat resection in patients with adrenocortical carcinoma. Annals of Surgical Oncology 6 719-726. (doi:10.1007/s10434-9990719-7)

von Slooten H, van Seters AP, Smeenk D \& Moolenaar AJ 1982 O, $\mathrm{p}^{\prime}$-DDD (mitotane) levels in plasma and tissues during chemotherapy and at autopsy. Cancer Chemotherapy and Pharmacology 9 85-88. (doi:10.1007/ BF00265384)
Southren AL, Tochimoto S, Isurugi K, Gordon GG, Krikun E \& Stypulkowski W 1966 The effect of 2,2-bis (2-chlorophenyl-4chlorophenyl)-1,1-dichloroethane (o, $\mathrm{p}^{\prime}$-DDD) on the metabolism of infused cortisol-7-3H. Steroids 7 11-29. (doi:10.1016/0039-128X (66)90132-2)

Sperone P, Ferrero A, Daffara F, Priola A, Zaggia B, Volante M, Santini D, Vincenzi B, Badalamenti G, Intrivici C et al. 2010 Gemcitabine plus metronomic 5-fluorouracil or capecitabine as a second-/third-line chemotherapy in advanced adrenocortical carcinoma: a multicenter phase II study. Endocrine-Related Cancer 17 445-453. (doi:10.1677/ ERC-09-0281)

Sun YF, Yang XR, Zhou J, Qiu SJ, Fan J \& Xu Y 2011 Circulating tumor cells: advances in detection methods, biological issues, and clinical relevance. Journal of Cancer Research and Clinical Oncology 137 1151-1173. (doi:10.1007/s00432-011-0988-y)

Terzolo M, Pia A, Berruti A, Osella G, Ali A, Carbone V, Testa E, Dogliotti L \& Angeli A 2000 Low-dose monitored mitotane treatment achieves the therapeutic range with manageable side effects in patients with adrenocortical cancer. Journal of Clinical Endocrinology and Metabolism 85 2234-2238.

Terzolo M, Boccuzzi A, Bovio S, Cappia S, De Giuli P, Ali A, Paccotti P, Porpiglia F, Fontana D \& Angeli A 2001 Immunohistochemical assessment of Ki-67 in the differential diagnosis of adrenocortical tumors. Urology 57 176-182. (doi:10.1016/S0090-4295(00)00852-9)

Terzolo M, Angeli A, Fassnacht M, Daffara F, Tauchmanova L, Conton PA, Rossetto R, Buci L, Sperone P, Grossrubatscher E et al. 2007 Adjuvant mitotane treatment for adrenocortical carcinoma. New England Journal of Medicine 356 2372-2380. (doi:10.1056/NEJMoa063360)

Toniato A 2013 Minimally invasive surgery for malignant adrenal tumors. Surgeon 11 253-257. (doi:10.1016/j.surge.2013.01.004)

Topalian SL, Hodi FS, Brahmer JR, Gettinger SN, Smith DC, McDermott DF, Powderly JD, Carvajal RD, Sosman JA, Atkins MB et al. 2012 Safety, activity, and immune correlates of anti-PD-1 antibody in cancer. New England Journal of Medicine 366 2443-2454. (doi:10.1056/ NEJMoa1200690)

Touitou Y, Bogdan A \& Luton JP 1978 Changes in corticosteroid synthesis of the human adrenal cortex in vitro, induced by treatment with $\mathrm{o}, \mathrm{p}^{\prime}$-DDD for Cushing's syndrome: evidence for the sites of action of the drug. Journal of Steroid Biochemistry 9 1217-1224. (doi:10.1016/ 0022-4731(78)90015-8)

Tran TB, Liou D, Menon VG \& Nissen NN 2013 Surgical management of advanced adrenocortical carcinoma: a 21-year population-based analysis. American Surgeon 79 1115-1118.

Urup T, Pawlak WZ, Petersen PM, Pappot H, Rorth M \& Daugaard G 2013 Treatment with docetaxel and cisplatin in advanced adrenocortical carcinoma, a phase II study. British Journal of Cancer 108 1994-1997. (doi:10.1038/bjc.2013.229)

Wood BJ, Abraham J, Hvizda JL, Alexander HR \& Fojo T 2003 Radiofrequency ablation of adrenal tumors and adrenocortical carcinoma metastases. Cancer 97 554-560. (doi:10.1002/cncr.11084)

Wortmann S, Quinkler M, Ritter C, Kroiss M, Johanssen S, Hahner S, Allolio B \& Fassnacht M 2010 Bevacizumab plus capecitabine as a salvage therapy in advanced adrenocortical carcinoma. European Journal of Endocrinology 162 349-356. (doi:10.1530/EJE-09-0804)

Zatelli MC, Gentilin E, Daffara F, Tagliati F, Reimondo G, Carandina G, Ambrosio MR, Terzolo M \& Degli Uberti EC 2010 Therapeutic concentrations of mitotane (o, $\left.\mathrm{p}^{\prime}-\mathrm{DDD}\right)$ inhibit thyrotroph cell viability and TSH expression and secretion in a mouse cell line model. Endocrinology 151 2453-2461. (doi:10.1210/en.2009-1404)

Received in final form 5 August 2015

Accepted 10 August 2015

Made available online as an Accepted Preprint

10 August 2015 http://erc.endocrinology-journals.org DOI: 10.1530/ERC-15-0318
(C) 2015 Society for Endocrinology Printed in Great Britain
Published by Bioscientifica Ltd 